\title{
Staff shortages and turnover: Causes and solutions
}

\section{Jill Poulston}

Jill is an Associate

Professor at the

Auckland University of

Technology, where she

studies a wide range of

ethical issues in

hospitality, such as

sexual harassment,

discrimination, and

ethical food

consumption. Prior to

this, she worked in

hospitality management, which included two

roles as a General

Manager. She currently

teaches leadership to

postgraduate students,

and supervises student

research projects.

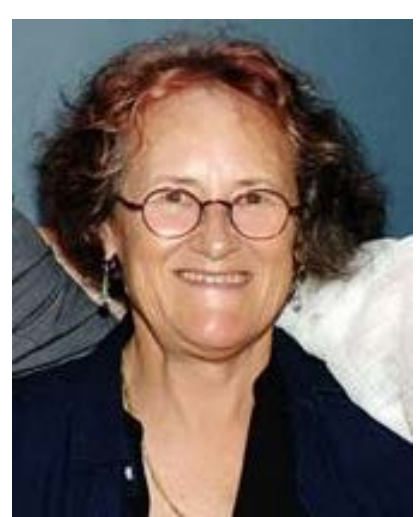

The New Zealand hospitality workforce is young; most are between 18 and 24 years old and attracted by the ease with which they can get work in a bar or restaurant. The work suits them; it is dynamic and easy to find, but many have no intention of staying in the industry. Hence, staff shortages and turnover are a constant problem for employers. However, the solution is not as difficult as one might imagine.

This study identified why there are so few older workers in the New Zealand hotel industry after interviewing 44 managers and older workers in New Zealand hotels and looking at Human Resources (HR) policies, recruitment methods, and selection criteria. The hotel industry was found to be discriminatory towards older job seekers in both principle and practice, even though some companies' policies appeared to address age discrimination. Interview data from the HR managers suggested older workers had the characteristics they were looking for, yet they were not specifically recruiting them.

Recommendations arising from the study focus around changing attitudes at senior level so older workers are perceived as potential employees. Recruitment processes need to be checked to make sure they do not disadvantage older job seekers, and senior managers need to be objective and consider the skills, abilities, and attitudes of older job seekers. Either of these simple changes could be made through training or well-supported policy and would positively affect the age profile and turnover of the industry's workforce.

Practical suggestions also include using older workers to mentor younger workers to promote communication across an age diverse workforce and allowing older workers to demonstrate and share their knowledge and experience. Combining older and younger workers in work teams may also help remove barriers by allowing older workers to impart some of their values through frequent interactions and working towards a common work goal. In-house training programmes may also help educate staff at all levels about the benefits of diverse workgroups.

Data from this and prior studies show that older people are ideal employees where good work attitudes [1] and well-developed soft skills [2] are important. Interestingly, prior research also shows that policy does not prevent discrimination, as it is too easily ignored. Recruitment methods such as 'Seek', Twitter, MyJobSpace.co.nz and word-of-mouth recruitment are discriminatory because they favour young people and act as barriers against the employment of older workers. 
Older recruits have much to offer, but in practice, their potential for employment is being restricted by recruiters' attitudes, as managers' views are more influential than policy. The challenge, therefore, is not so much in what needs to change, but how to make changes to reduce or eliminate discrimination in hotels against older job seekers.

More information about this study is in the original article [3], which can be obtained from the authors.

\section{Corresponding author}

Jill Poulston can be contacted at: jill.poulston@aut.ac.nz

\section{References}

(1) Ng, T. W. H.; Feldman, D. C. The Relationships of Age with Job Attitudes: A Metaanalysis. Personnel Psychology 2010, 63(3), 677-718. https://doi.org/10.1111/j.1744$\underline{6570.2010 .01184 . x}$

(2) Sissons, P.; Jones, K. Lost in Transition?; The Work Foundation: Lancaster, U.K., 2012.

(3) Poulston, J.; Jenkins, A. Barriers to the Employment of Older Hotel Workers in New Zealand. Journal of Human Resources in Hospitality \& Tourism 2016, 15(1), 45-68. 